\title{
Optimal Control Strategy for a Marine Current Farm Integrated with a Hybrid PV System/Offshore Wind/Battery Energy Storage System
}

\author{
Adel Elgammal, Miguel Jagessar
}

\begin{abstract}
This paper suggests an automated control technique constructed on the Multi-Objective Particle Swarm Optimization to enhance the operation of a wind farm, a marine power plant and a photovoltaic array with a battery energy storing system. due to changes in PV / wind / tide, and to boost the efficiency of offshore wind farms and marine power stations connected to the battery-powered storage system, with a view to smoothing power production, the aim of projected automatic control strategy is to minimize power fluctuations and voltage variations. The battery energy storage network was used with an optimized demand response strategy based on the real-time pricing model to improve stability and power efficiency, reduce the power fluctuations and variations in bus voltage and address renewable energy generation instability. The multi-objective particle swarm optimizationbased energy management programming model would be used to minimize running costs, pollutant emissions, increase the demand response benefits of micro grid operators and, at the same time, meet the load demand constraints from customers of all sorts, such as domestic, commercial and industrial users.
\end{abstract}

Index Terms - Battery Energy Storage System, Renewable Energy integration, Multi-Objective Particle Swarm Optimization, Marine Current Farm, PV system, Offshore Wind Farm.

\section{INTRODUCTION}

Ocean energy covers numerous renewable sources, such as marine, tidal, solar, wave power, and offshore wind. marine-current plant and Offshore wind farm will be broadly built at different sites across the globe over the coming years, covering more than $70 \%$ of the earth 's atmosphere [1] for power supply and has been implemented effectively in many developed nations, photovoltaic, wind and ocean power generated energy is well suited. In the case of a distribution grid, battery bank is required to supply backup power when renewable energy generation begins to fail [2]. Offshore wind turbines will be paired with marinecurrent turbine generators to create a new development in the generation of significant electricity. The integration of high-capacity wind and marine resources supplied to an electricity system raises a variety of challenges, such as large-scale instability, resource quality, unreliable power systems, forecasts of random wind production and the transition to conventional power plant operating strategies [3].

Published on August 31,2020.

Adel Elgammal, The University of Trinidad and Tobago UTT, Trinidad and Tobago.

(corresponding e-mail: adel_elgammal2000@yahoo.com)

Miguel Jagessar, The University of Trinidad and Tobago UTT, Trinidad and Tobago.
The configuration of the ocean wave energy is generated by a Double Fed Induction Generator ( DFIG), while new underwater farm technologies are provided by a squirrelcage induction generator (SCIG). To achieve maximum output from the available wind power, the efficiency analysis \& differentiation among permanent velocity and variable velocity wind turbines together with the power network and capacity of variable velocity structures was seen in the [4]. To increase the integrated offshore wind farm's dynamic performance, a planning and control scheme was suggested in combination with Marine-Current Farm and an electricity grid using a Flywheel energy storage network would reduce demand volatility at the same time [5]. Implementation of electronic control equipment and integrated AC transmission system (FACTS) technologies in the supply and transmission network will ensure an efficient static and dynamic voltage, power and PQ stability management [6]. To shift grid current and line and create free harmonic current, distributed generation with a gridconnected inverter power flow control problem, in which phase-locked loop algorithm was developed [7]. The power supply configuration of the Pulse Width Modulation Input Inverter variant attached to the supply has an effective converter control mechanism that not only relays direct current from the grid, but also increases the load factor and adjusts the output voltage meter [8]. The power grid should be made reliable and the true $\&$ reactive power flow into a single power flow generator in the direction of the transmission and distribution network within the range [9][10]. Improve the complex stability and instability of the bus voltage in the power system network (including solar wind farms and marine current farms as energy sources) developed by STATCOM using a pole-based PID damping device. [11]-[12]. In DFIG, the wind energy network performed a steady state study with specific wind speeds and maximum power point regulation (using fixed speed \& variable speed at wind turbine) [13]. Improving marine current turbine output depends on speed \& pitch power. This method of use was discussed with complex load assessment of various operating points and improved performance [14] Development of the energy storage network of a wind farm is seen as a reasonable option for smooth power variability and the provision of auxiliary grid services [15], [16]. In [17] and [18] respectively, the battery and super capacitor (SCs) are investigated to smooth the power variations and accommodate the changes in load demand for wind turbines. The application of cell and SC ESS method for electric power efficiency and battery life is investigated in [19]. Different ESS technologies for marine energy applications were compared and evaluated in [20], and the authors 
concluded that SC technology is ideally suited for smoothing short-term power fluctuations in MCT systems due to its high performance and high dynamic characteristics. Both DC-to-AC inverter and DC-to-DC converter are utilized to efficiently transform the energy generated using double-layer electrical condensers to account for the volatility of the wind farms studied [21, 22]. The properties of various energy storing structures on wind turbines were also contrasted in [23], [24]. DFIG-based PID monitoring was introduced for MCT velocity tracking [25]. The PID controller is highly recognized for its ease of comparison and robustness. Though, in the situation of MCT, the reference signals produced differ in the current sources, and time can be unreliable, making PI feedback inefficient. Based on the characteristics of tidal tools for example friction and swelling impacts and unavoidable volatility inherent in DFIG-based MCTs, non-linear and reliable control methods such as sliding mode control appear to be a successful solution to optimizing system efficiency and reliability [26], [27]. In addition, since sliding mode control delivers structure dynamics with the invariant property before sliding system dynamics are controlled, it is one of the essential nonlinear resilient control methods. [28]. Sliding mode should provide an effective control device to increase performance and smooth torque oscillation with DFIG-based MCTs [29], [30].

This paper represents an optimized management technique for rapidly reducing voltage differences and power fluctuations as a result of shifts in wind/wind strength and optimizing the output of offshore wind farms and marine grid-connected power farms with battery storage network to ensure smooth development. Through using the battery energy storage network or information systems with proper control methods, appropriate converter and variable speed induction generators function, improvement of vehicle reliability, minimization of power fluctuations and improvement of bus voltage. This project seeks to evaluate the optimum operation of the smart micro grid with the goal of reducing running costs and emissions and increasing the reliability of smart micro grid results. This also seeks to understand the concept of a demand response strategy based on the real-time pricing model in smart grids to cover the variability generated by $\mathrm{PV} /$ wind/tide power generation and understand the usual behavior of stochastic.

\section{TYPICAL OFFSHORE PV SYSTEM, WIND FARM, MARINE CURRENT FARM AND BATTERY CONFIGURATION SYSTEM}

This paper describes the control mechanism for a DCconnected hybrid power network utilizing three sources of power generation, PV system, offshore wind and marsh turbines. The electricity is generated from PV, offshore wind and tidal energy, and distributed to a charging network afterwards. Power quality issues including frequency fluctuations and voltage shifts induced by faults or pulsed loads can lead to critical load interruptions. The reliability of offshore wind power grid may be a serious concern. In the proposed system, the PSMG for wind and marsh turbines can function as a generator for mitigating frequency and active power fluctuations. This paper discusses the basic device setup, the simulation results and a review of the proposed system's general operating performance. Offshore wind turbine systems have significant feature whereby offshore wind turbines generate energy without pollution. Renewable power systems are affected by generation-side fluctuations caused by the seasonal and random nature of the energy resource. Charges often have complex capacity needs at the same time. In this case, marsh turbine for hybrid integration and automated fluctuation adjustment play a significant role in generation and demand matching. Figure displays the design of the proposed system with the suggested energy storage network controller with an integrated PV, marine current farm. The 10-KW offshore wind farm and the 15-KW underwater current farm denoted a related PSMG powered by an analog gearbox with a variable speed wind turbine. To increase the continuous power supply and keep the unit stable, the 5KW PV system is connected to the grid via charging controller and inverter. Using step-down / step-up transformers, underground cables and transmission lines, the offshore wind farm, coastal power station, photovoltaic network, energy storage facility and charging system is paired with an AC automobile supplied to power network. A bidirectional, 6-pulse IGBT converter converts the AC power produced by the offshore wind and tidal turbine to DC. To keep surplus energy in the storing network, the DC transmission line is connected to the PWM inverter and then using the three-phase converter bridge, converts the required grid power to AC. The DC power is transferred to AC by mean of 6 pulsed IGBT inverter. If excess power is available, a three-phase converter can return it to the storage scheme. The DC power generated by the PV network is transmitted through the DC connection, and the PV arrangement is continuously shared with these (OWF \& MCF) capacities during demand to ensure continuous grid accessibility. Furthermore, to trigger the squirrel cage generator to work, the LC filter is connected to the transmission line to flush out the harmonics. The PV/OWF/MCF machine configuration consists of a three-bladed turbine that is attached to the PSMG variable speed. The dc-bus condenser is connected between them, in which two converters from voltage sources make up the back-back converter. The converter called MSC Module Side Converter is installed between PSMG and the DC-bus condenser. This MSC is also used for the production of PSMG system fluxes to maximize wind energy capture. The other Grid Side Converter GSC converter is held between the DC-bus condenser and the battery. The converter aims at standardizing the DC-bus voltage and the movements of both reactive and active electricity. To adjust dc-bus energy by charging the condenser while the voltage is dc-bus, the GSC has also been used as a rectification device. The DC-bus voltage rises and the GSC invertly regulates the DC connection voltage, if electricity is present in the setting. Yet power flows also transfer electricity to the distribution grid from the DC-bus. The AC currents and voltages are sent to $d-q$ modules in order to phase the voltage and the currents to match the frequency between grid side and device side voltages. The MSC machine-side converter aims at achieving ideal torque by MPPT and providing critical magnetizing current to PSMG. Fig. 2-4 displays the MCF, OWF, and PV control system approach. Grid side inverter features DC contact control. The flow control loop controls 
the current loop on the direct axis and the flow control loop regulates the flow loop, in order to enable the drive to operate continuously in the field weakening area while retaining a steady rotor amplitude output and absolute rotor speed value. In the quadrature axis the present counter is controlled with a speed counter. The MPPT method obtains the reference speed of the machine which corresponds to the theoretical strength of the machine at a given marine level. This has the mean torque and average unit velocity as input and provides the unit the reference velocity as output. Grid side converter research was conducted with the intention to automatically decouple the direct and quadrature components of the injected current operating within the reference frame of the grid voltage vector. As the intention here is to regulate the DC touch voltage exclusively, the regulate role was changed by adding another control loop, the one with the direct reference current output. The reference quadrature current is zero and the complex power flow across the system will be held at zero. The generator function is programmed to regulate the speed of the reference rotor to fulfill the power provided by the MCT. The turbine-side transformer allows the torque motor to drive the rotor rpm. The current relation -axis is set to zero, to optimize the generator's active capacity. The velocity loop generator defines the present reference-axis. MPPT requires increasing the rotor's speed to attain the optimal turbine tip speed ratio while preserving the average turbine performance coefficient. If the curve is defined and the flow rate of the marine current can be calculated, the ratio of the turbine velocity measured by MPPT can be stated as:

$$
\omega_{\text {ref }}=\frac{\lambda_{\text {opt }} V}{R}
$$

The basic concept of the proposed MPPT approach is to obtain the generator's optimum reference speed for each instant marine speed value (meaning the speed equal to the maximum generable power). It makes the use of an MPPT strategy based on the speed control of the machine instead of its torque power, with all the resulting advantages in a smoother and more efficient operation of the entire system. The instantaneous values of the sea shall be measured in advance to determine the optimum reference velocity of the unit. Knowledge of these statistics is also important for other characteristics of marine generators (provides information on proper behavior within the complete permissible range of marine speeds and can therefore detect generator disconnections where necessary). The reference speed of the generator will be calculated according to the following expression before the sea level is measured:

$$
\omega_{r e f}=\frac{\lambda_{o p t} V}{R}
$$

Where $\omega_{\text {ref }}$ is approximate sea level and $\lambda_{\text {opt }}$ is the ideal ratio of tip rpm, a known quantity and based on turbine characteristics.

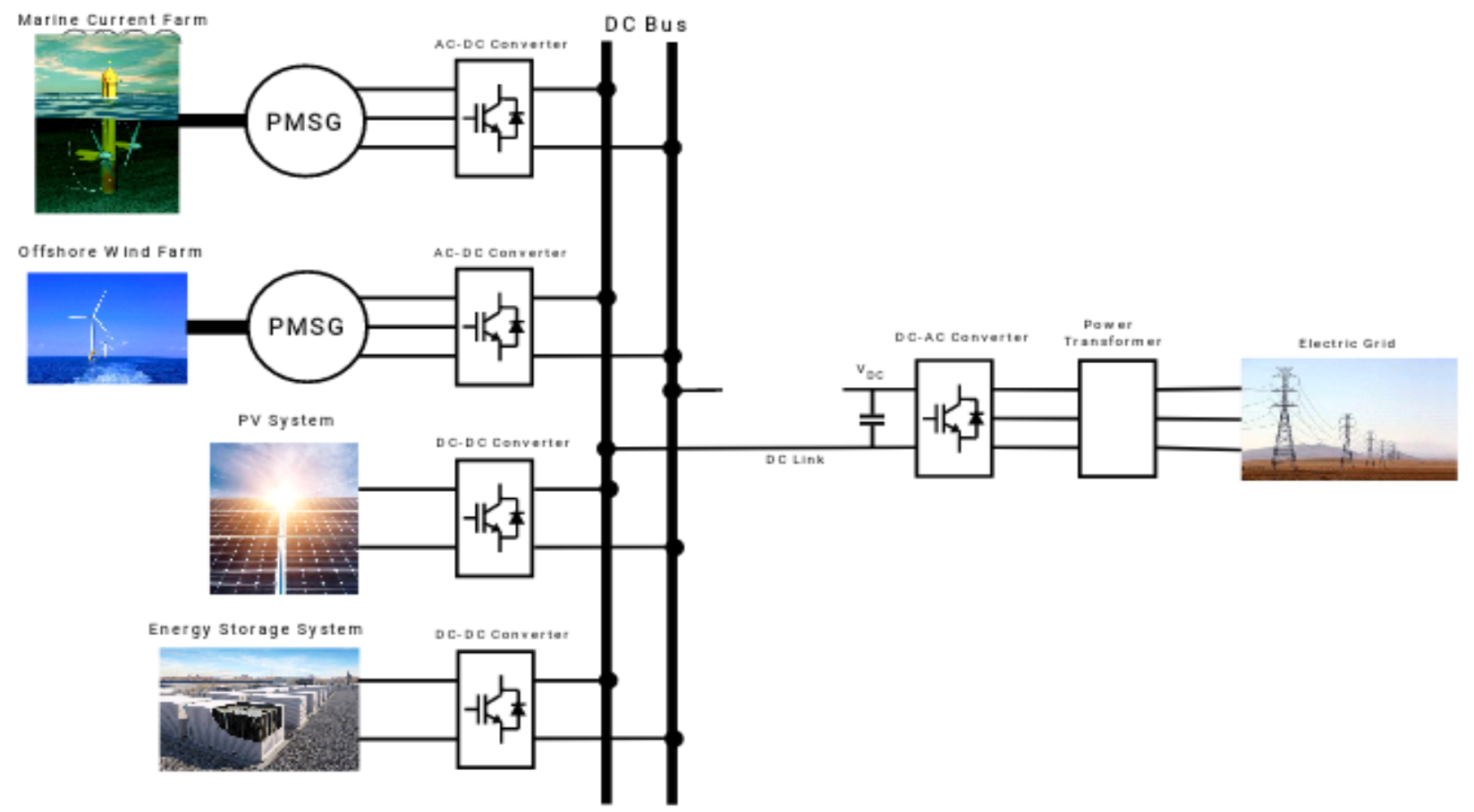

Fig. 1. With FESS, configuration of the Integrated, PV system, MCF and OWF. 


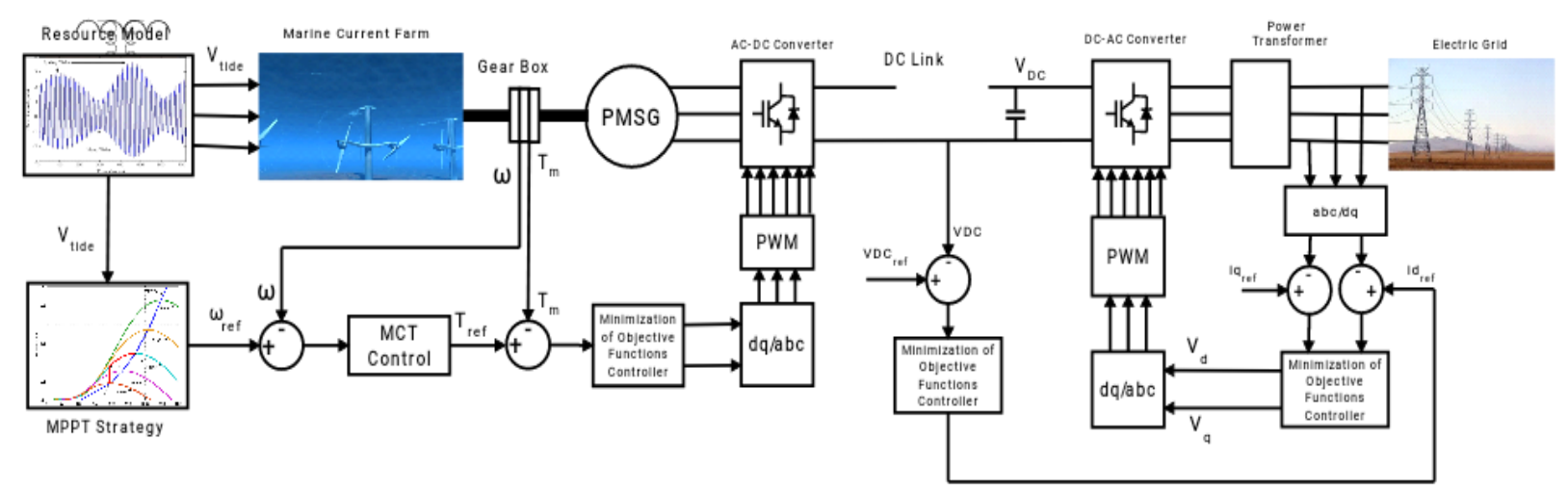

Fig. 2. For a PMSG-based Marine Current Farm, Variable-speed control.

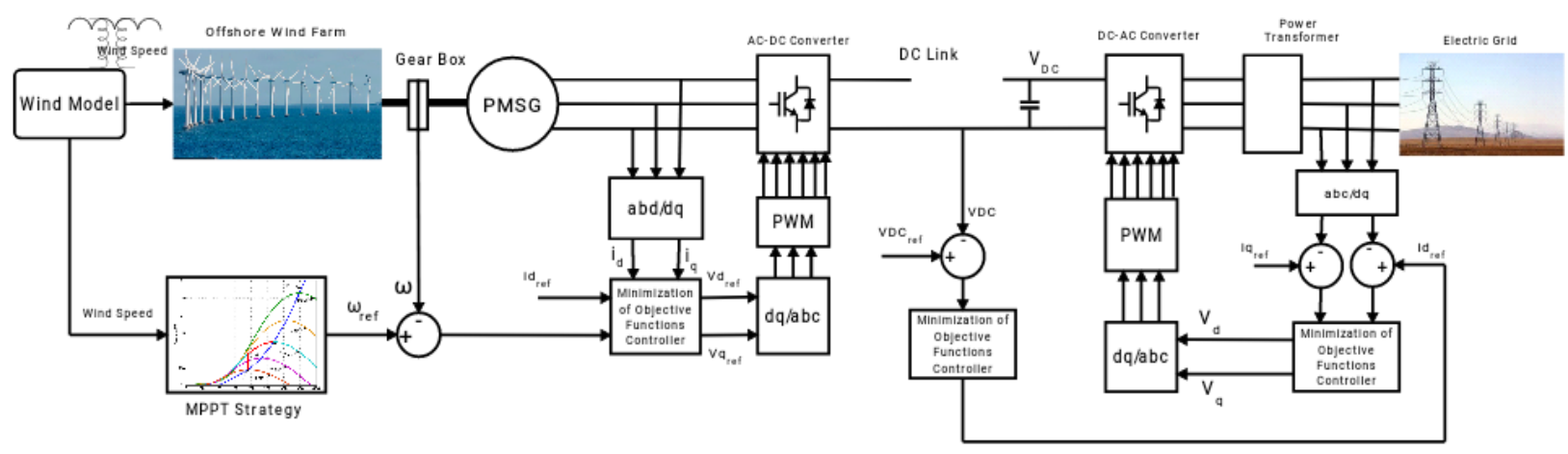

Fig. 3. Variable-speed control for a PMSG-based Offshore Wind Farm.

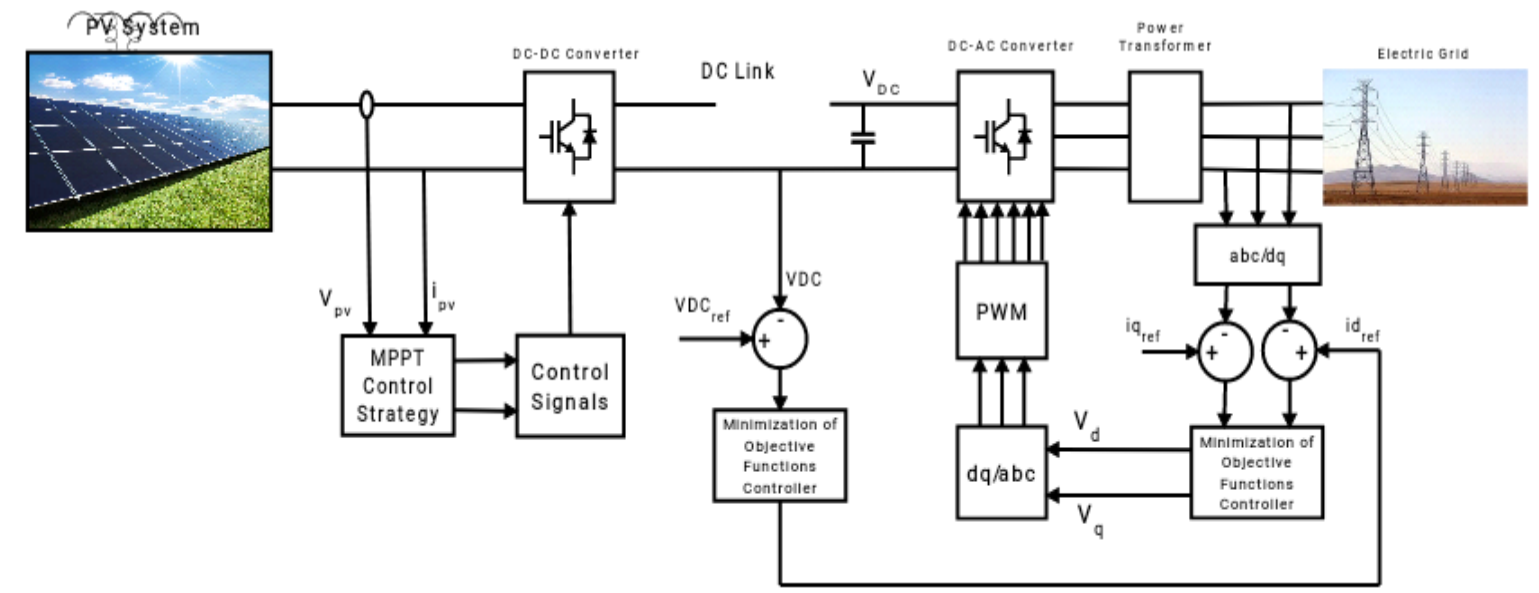

Fig. 4. PV system control scheme and System configuration.

\section{Overall CONTROL Algorithm}

The suggested overall control block diagram consists of two sections: one for the existing dc regulation of the dc bus interface converter and the other for the side control of the system. There are two grid side regulators for speed and controlling the magnitude of rotor flux, respectively. This then produces the existing stator reference matrix. To calculate the rotor flux vector, a current-model rotor flux estimator used. In this structure, the dc-link current is also sensitive to the lack of the switching. The reference $\mathrm{dc}$ current is measured and sent to network converter dc rail. The torque and the rotor flux strength are known with the analysis of the stator current relation. Costing functions can also be expressed as:

$$
J_{1}=\left|i_{d}^{r e f}-i_{d}(k+1)\right|^{2}
$$

$$
J_{2}=\left|i_{q}^{r e f}-i_{q}(k+1)\right|^{2}
$$

The MOPSO is introduced in this configuration to increase the operational performance, in particular the dynamic response of the dc bus interface converter. The dc current in the proposed method relates to dc-side voltages, and with the information of the calculated dc current and dcside voltage at kth instant at each measurement interval, the dc current at $(\mathrm{k}+1)$ th instant can be estimated using the theoretical output dc interface voltage converter. The utility of the shift in gains is determined by an equation reflecting the weighted average of the variables of Normalized Mean Square Error (NMSE) between the production plant and the target values. This way the goal of optimizing system efficiency during intermittent fluctuations can be accomplished by determining optimum values for the gains from the controller. The NMSE variations between the plant 
production variables and the target values are defined as:

$$
\begin{aligned}
& J_{3}=N M S E_{\omega r}=\frac{\sum\left(\omega_{r}-\omega_{r-r e f}\right)^{2}}{\sum\left(\omega_{r-r e f}\right)^{2}} \\
& J_{4}=N M S E_{V D C}=\frac{\sum\left(V_{D C}-V_{D C-r e f}\right)^{2}}{\sum\left(V_{D C-r e f}\right)^{2}} \\
& J_{5}=N M S E_{I D C}=\frac{\sum\left(I_{D C}-I_{D C-r e f}\right)^{2}}{\sum\left(I_{D C-r e f}\right)^{2}}
\end{aligned}
$$

The SOPSO provides a single ideal or near-optimal solution based on one weighted purpose. The weighted single objective function (Jo) combines various objective functions using the following weighting factors:

$$
\mathrm{J}_{\mathrm{o}}=\int_{0}^{\mathrm{t}}\left(\alpha_{1} J_{1}+\alpha_{2} J_{2}+\alpha_{3} J_{3}+\alpha_{4} J_{4}+\alpha_{5} J_{5}\right) d t
$$

Where the weighting factors $\alpha 1, \alpha 2, \alpha 3, \alpha 4$, and $\alpha 5$ are chosen. Selected objective functions are J1, J2, J3, J4, J5. The Objective function (Jo) weighting factors are used to satisfy various design requirements. By using a high value of $\alpha 1$, the goal is to decrease the error in the DC connection voltage. In comparison, MOPSO and MOGA find the set of suitable Optimal Solutions (trade-offs). This set of agreed solutions is dubbed Front Pareto. Such suitable multi-level trading strategies allow the customer more opportunity to make educated decisions by having a large variety of virtually ideal solutions. The key stages of an efficient PID controller using MOPSO to obtain design system are an iterative scheme with the following steps:

1. Initialize the particulate swarm population with arbitrary gain values that correspond to the set of variables for the decision.

2. Test every particle for viability. If the particle fails to fulfill the limits, then rebuild it.

3. Particulate swarm velocities are initialized with random values.

4. For associated target functions, the fitness of every particle in the swarm is calculated. The PID controller wins are allocated to each person and the WECS-DFIG model is simulated to obtain the objective function values.

5. Evaluate, and store in vector form, the multi-objective fitness value of each particle. These vectors store the values of each acquired PID controller from which the particles in a Pareto sense get the best values. At this algorithm stage these vectors are loaded with the output of initial evaluations of the particles. Such values are converted into pbest vectors.

6. For each particle, determine multi-objective fitness values, and evaluate the optimal Pareto. This eliminates all non-occupied particles in the Pareto directory (external file)

7. A random collection of the best particle in the universe.

8. This changes the velocities of each particle. Two Pareto alternatives are selected at random from the Pareto database.

9. Adjust the position of each atom, sometimes. The particles are kept within appropriate values for the size. That mutates the spores, then. When the molecule will not function in the solution field it will be destroyed and degraded again.

10. For each particle calculate the multi-objective fitness value. Check the optimality of Pareto on all particles. If the particle's fitness score is undominated by the maximal Pareto collection in the database then add it to Pareto 's list. If a particle in Pareto 's Archive is replaced by a new one then delete it.

11. The latest gbest is then picked at random. Two Pareto solutions are randomly chosen from Pareto database.

12. Start the series, steps (8) to (11) before using the desired single or multiple parameters to obtain the predetermined maximum number of generations or convergence

\section{DIGITAL STIMULATION RESULTS}

Developed and tested by Matlab/Simulink Software's Sim Power System toolbox, MOPSO-based control technique for PV / wind / marine generation network with PMSG. The proposed MOPSO strategy has been checked for validity and adopted to produce a clear power comparison and verify the efficiency of good power monitoring and thus confirms the efficacy of the proposed MOPSO based control strategy. Comparing the changes in the system's complex performance with the use of the MOPSO technique to develop the controller's benefits, these results are contrasted with those achieved with MOGA. The MOGA and MOPSO were used with the same operational environment to achieve optimum gains for the stator-side controllers and the rotorside converters. There are four PID controllers in the GSC and RSC control loops, each with an additive gain, an integral and conditional gain. The Converter's action depends on the control mechanism. If the controllers are properly tuned, the efficiency of the GSC and RSC converters during transitory disruptions can be improved. Yet tuning controllers are repetitive and it's hard to manually obtain a range of optimum parameters. The MOGA and the MOPSO algorithms are used to dynamically determine the optimal parameters for the GSC and RSC controllers. The goal of the MOGA and MOPSO is to determine the optimum parameters of the four PID controls, i.e. four additive gains (KP1, KP2, KP3 and KP4), four intrinsic gains (KI1, KI2, KI3 and KI4) and four conditional gains (KD1, KD2, KD3 and KD4) to optimize these exercise functions. The goal is to increase the overall complex efficiency of the PMSG as it is exposed to extreme electrical disruptions and defects in the electrical network in determining the optimal benefits by the GA and the PSO procedures. The following changes have been made to demonstrate the efficacy of the current MOPSO strategy. To the marine generation system, a number of variations in sea level were provided, which primarily worked at a steadystate at sea level of $4 \mathrm{~m} / \mathrm{s}(1 \rightarrow 2 \rightarrow 4 \rightarrow 3 \rightarrow 1 \rightarrow 4 \mathrm{~m} / \mathrm{s})$. Fig. 5 indicates actual sea level. It should be remembered that the projected velocity reliably matches the real one and almost immediately converges to it. Figure 6 correspondingly displays the comparison and calculated rotor speed that is increased or decreased as a function of the rise or decrease in the average sea level to track the MPP. It is found that the PMSG runs always at the optimal reference speed for any 
given flow rate. The grid side isd, isq relationship and calculated currents as well as the active $(\mathrm{P})$ and reactive $(\mathrm{Q})$ energy flowing through the power grid are seen in Fig. 7-10. They display that the current isq and the reactive $Q$ are reduced to zero, stressing that there is no exchange of reactive power with the power grid. In contrast, the isd current portion and active power $\mathrm{P}$ increase as expected with some improvement in sea level. The system always yields maximum power at any speed of flow. The controller suggested therefore also runs the device at full power point. These simulation findings demonstrate that with tidal turbine, the hybrid generation system is successful in combining and compensating for automatic power fluctuation. Fig. 11 indicates the torque which was generated by the system. The MOPSO dependent controller ensures that the torque and the input current produced strictly obey the torque of the reference generator and the current of the commands. It should be remembered that the generator reference torque direction also meets the optimal torque at the turbine. Thus, the optimum turbine torque can always be tracked at any flow speed using the control strategy proposed by MOPSO without the use of any flow sensors. Fig. 12 also displays hybrid-side DC voltage (Vdc V). Such simulation results show a very robust DC voltage for the hybrid generating system. Finally, Fig. 13-17 show AC side current performance and voltages. The proposed controller therefore provides good steady state and volatile efficiency and has excellent monitoring capabilities.

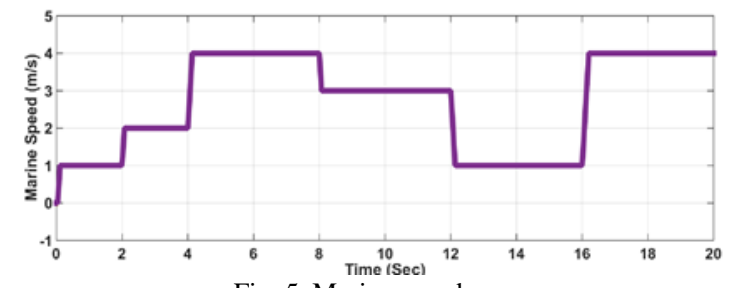

Fig. 5. Marine speed.

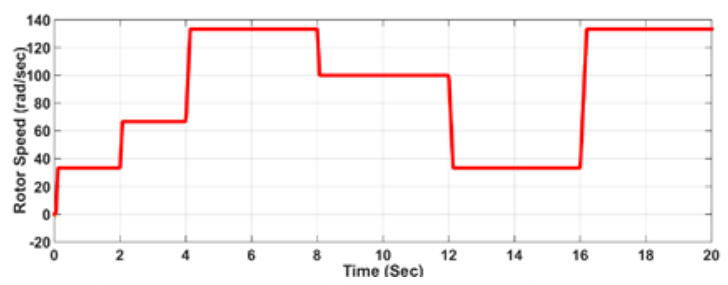

Fig. 6. Measured machine speed and Reference.

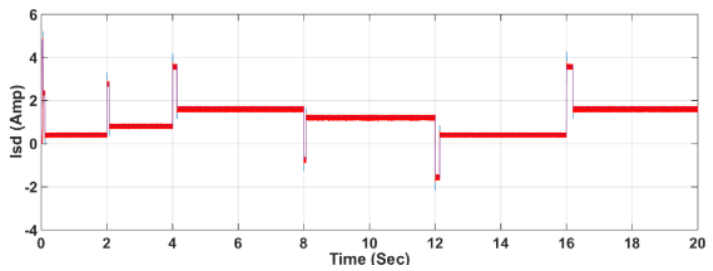

Fig. 7. Measured currents and grid side isd reference.

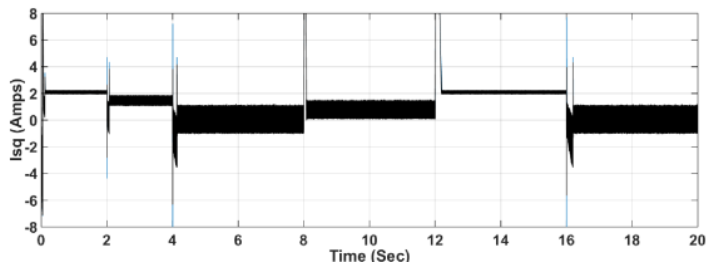

Fig. 8. Measured currents and grid side isq reference.

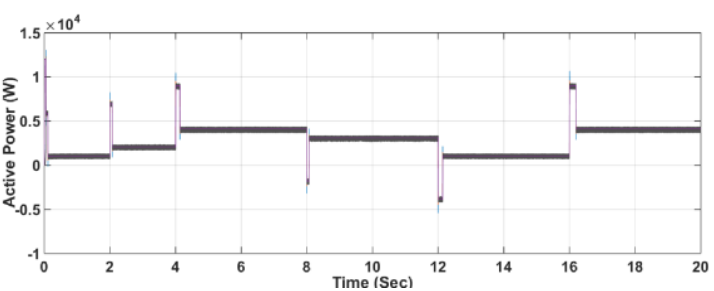

Fig. 9. Active power $(\mathrm{P})$ shared over the power grid.

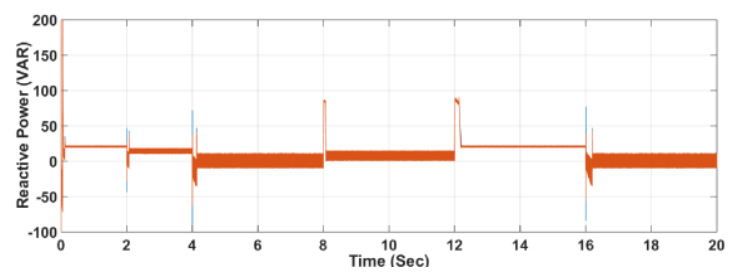

Fig. 10. Reactive power (Q) exchanged over the power grid.

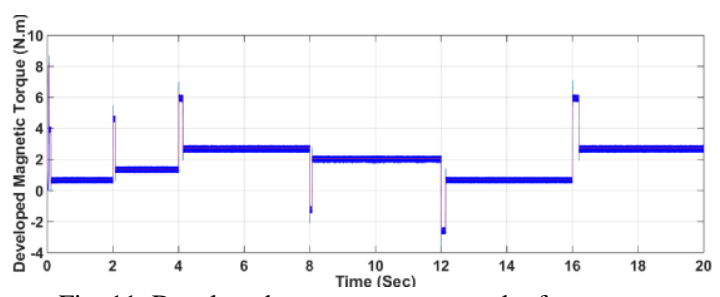

Fig. 11. Developed generator torque and reference.

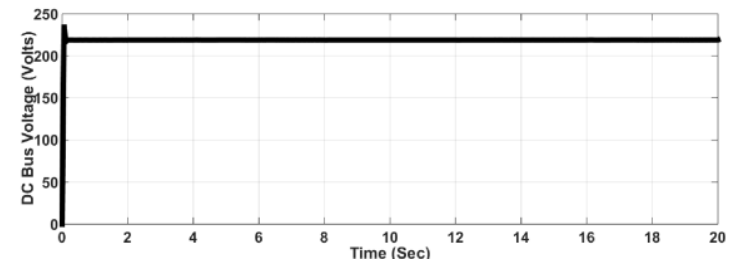

Fig. 12. Measured DC Bus Voltage and Reference.

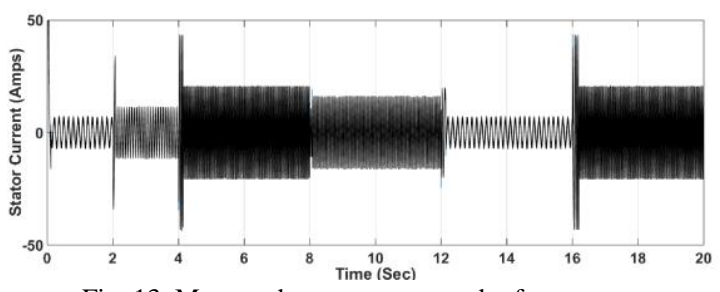

Fig. 13. Measured stator current and reference.

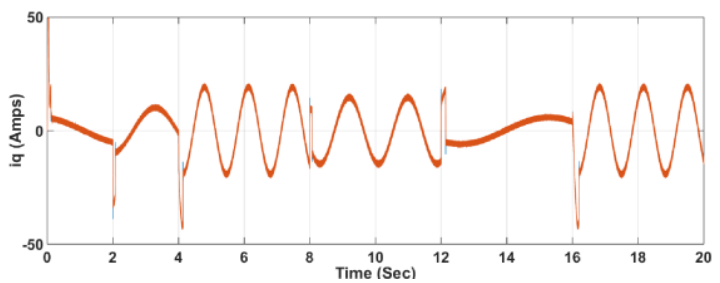

Fig. 14. Reference and measured iq

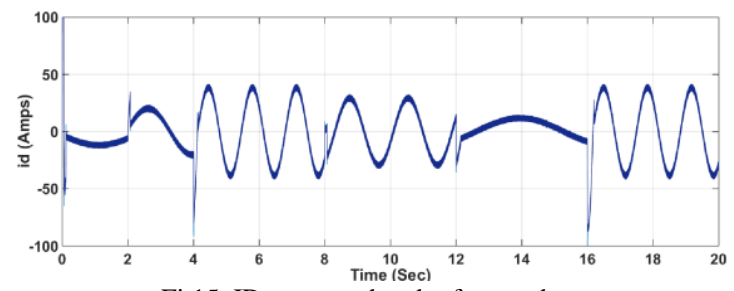

Fi 15. ID measured and referenced. 


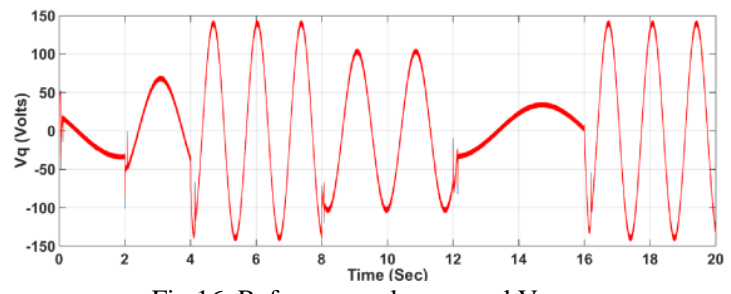

Fig 16. Reference and measured Vq

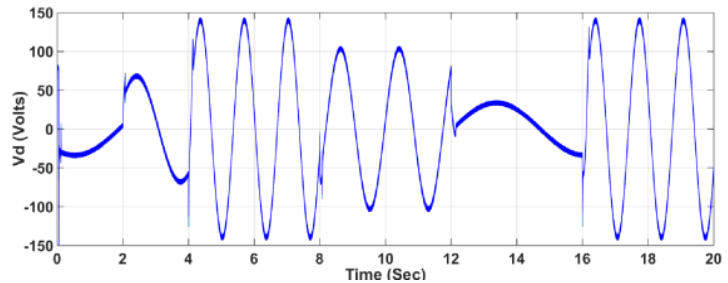

Fig. 17. Reference and measured Vd.

\section{CONCLUSION}

Due to shifts in PV/wind/tide ratios, this paper outlines an important monitoring method for quickly reducing changes in demand and voltage variations. This also explains the methodology used to improve the performance of marine power plants and offshore wind turbines linked to the network of battery power storage systems to ensure steady output capacity. By using the battery-energy storage network and Data systems with correct control methods, variable speed PMSG and efficient converter control, system performance enhancement, power fluctuation minimization and improvements in bus voltage can be accomplished. The MOPSO 's key goal is to automate smart micro grid service with a view to reducing running costs and emissions and increasing the efficiency of smart micro grid output. Consideration of the concept of a demand response approach based on the smart grid real-time pricing mechanism to fix the confusion created by the generation of PV / wind / tide and take stochastic natural behaviour. The findings obtained are very positive. Simulation experiments have also shown the effectiveness of the suggested control technique in reducing differences in bus voltage and power management. In other words, when the resource is severely compromised and the resource is not well known, MOPSO control has been seen to be a good option.

\section{REFERENCES}

[1] Johanne Tomine Vartdal ; Raad Yahya Qassim ; BØrge Mokliev ; Guttorm Udjus ; Eduardo González-gorbeña "Optimal configuration problem identification of electrical power cable in tidal turbine farm via traveling salesman problem modeling approach" Journal of Modern Power Systems and Clean Energy, Year: 2019, Volume: 7, Issue: 2 .

[2] Li Wang; Mi Sa Nguyen Thi “Comparative Stability Analysis of Offshore Wind and Marine-Current Farms Feeding Into a Power Grid Using HVDC Links and HVAC Line" IEEE Transactions on Power Delivery, Year: 2013, Volume: 28, Issue: 4.

[3] Satendra Kumar Singh Kushwaha ; Soumya R. Mohanty ; Paulson Samuel "Robust $\mathrm{H} \infty$ control for stability assessment in gridconnected offshore wind and marine current hybrid system" IET Renewable Power Generation, Year: 2019, Volume: 13, Issue: 2.

[4] Phan Dinh Chung "Comparison of Steady-State Characteristics between DFIG and SCIG in Wind Turbine", International Journal of Advanced Science and Technology, Vol. 51, February, 2013.

[5] Wang.L, Chen .Y-T (2011) "Dynamic Stability Improvement of an Integrated Offshore Wind and Marine-Current Farm Using a
Flywheel Energy-Storage System”, IEEE Trans. Energy Convers., pp. 626-639.

[6] Jogi Sindhura "Improve the Dynamic Stability of an Integrated GridConnected Offshore Wind Farm and Marine-Current Farm Using FACTS", International Journal of Engineering Research \& Technology, Vol. 1, Issue 7,2012,ISSN: 2278-0181.

[7] Min Dai, Mohammad Nanda (2009) "Power Flow Control of A Single Distributed Generation Unit", IEEE Trans. Power Electronics, Vol. 23, No.1.

[8] Sivaram.S et al (2014) "Power Quality Analysis in Hybrid Energy Generation System", Inter.Journal of Advance Research In Computer Science, Vol. 2, Issue 1.

[9] Vijayanandh.A, Santhosh Kumar.T, "Stability Analysis Of An Integrated System Connected To A Grid Using A Unified Power Flow Controller", International Journal Of Innovative Research In Science, Engineering And Technology, Vol 3, Issue 1, 2014.

[10] G.Satyanarayana et al "Analysis of Wind Farm to Weak-Grid Connection Using Fuzzy Based Unified Power Quality Compensator Int.J.Computer Technology \& Applications", Vol 3 (3), 978-986, 2012.

[11] Chia-Tien Hsiung et al "Dynamic Stability Improvement of an Integrated Grid-Connected Offshore Wind Farm and Marine-Current Farm Using a STATCOM" IEEE Trans on power systems, vol.26, no.2,2011.

[12] Srinivasa acharya "Analysis of STATCOM Controlled PMSG Based on Shore Wind Farm and Off Shore Wind Farm for Dynamic Stability Improvement" Int.J.Elect, Electronics and Ins Eng.,Vol. 2, Issue 8, 2013.

[13] Bharathi Dasan.S.G"Steady State Analysis of Grid Connected Wind Energy Conversion Systems", IEEE Trans on Power Sys., vol 15, no.1, pp.110-115,2008

[14] Elghali.S.E et al "A Simulation Model for the Evaluation of the Electrical Power Potential Harnessed by a Marine Current Turbine", IEEE, Oceanic Engg., vol 4, pp.786-797, 2007.

[15] S. Vazquez, S. M. Lukic, E. Galvan, L. G. Franquelo, and J. M. Carrasco, "Energy storage systems for transport and grid applications," IEEE Trans. Ind. Electron., vol. 57, no. 12, pp. 38813895, Dec. 2010.

[16] Y. Cheng, "Super capacitor applications for renewable energy generation and control in smart grids," in Proc. 2011 IEEE ISIE, Gdansk, Poland, Jun. 2011, pp. 1131-1136.

[17] A. Abedini and H. Nikkhajoei, "Dynamic model and control of a windturbine generator with energy storage," IET Renew. Power Generat., vol. 5, no. 1, pp. 67-78, 2011.

[18] L. Qu andW. Qiao, "Constant power control of dfig wind turbines with supercapacitor energy storage," IEEE Trans. Ind. Appl., vol. 47, no. 1, pp. 359-367, Jan./Feb. 2011.

[19] W. Li, G. Joós, and J. Bélanger, "Real-time simulation of a wind turbine generator coupled with a battery supercapacitor energy storage system," IEEE Trans. Ind. Electron., vol. 57, no. 4, pp. $1137-$ 1145, Apr. 2010

[20] Z. Zhou, M. E. H. Benbouzid, J. F. Charpentier, F. Scuiller, and T. Tang, "Energy storage technologies for smoothing power fluctuations in marine current turbines," in Proc. 2012 IEEE ISIE, Hangzhou, China, May 2012, pp. 1425-1430.

[21] Kinjo, T., Senjyu, T., Urasaki, N., Fujita, H.: 'Output levelling of renewable energy by electric double-layer capacitor applied for energy storage system', IEEE Trans. Energy Convers., 2006, 21, (1), pp. 221-227.

[22] Ushiwata, K., Shishido, S., Takahashi, R., Murata, T., Tamura, J.: 'Smoothing control of wind generator output fluctuation by using electric double layer capacitor'. Proc. Int. Conf. Electrical Machines and Systems, Seoul, Korea, 8-11 October 2007

[23] Yang, B., Makarov, Y., Desteese, J., Viswanathan, V., Nyeng, P. McManus, B., Pease, J.: 'On the use of energy storage technologies for regulation services in electric power systems with significant penetration of wind energy'. Proc. 5th Int. Conf. European Electricity Market, 28-30 May 2008.

[24] Spahic, E., Balzer, G., Hellmich, B., Munch, W.: 'Wind energy storages - possibilities'. Proc. Power Tech 2007 IEEE, Lausanne, 1-5 July 2007, pp. 615-620.

[25] S. E. Ben Elghali, M. E. H. Benbouzid, J. F. Charpentier, T. AhmedAli, J. M. Gahery, and A. Denis, "Modeling and MPPT sensorless control of a DFIG-based marine current turbine," in Proc. Int. Conf. Electr. Mach., Vilamoura, Portugal, Sep. 2008.

[26] M. M. Hand, K. E. Johnson, L. J. Fingersh, and A. D. Wright, "Advanced control design and field testing for wind turbines," Nat. Renewable Energy Lab. (NREL), NREL/CP-500-36118, 2004. 
[27] Y. D. Song, B. Dhinakaran, and X. Y. Bao, "Variable speed control of wind turbines using nonlinear and adaptive algorithms," J. Wind Eng. Ind. Aerodyn., vol. 85, no. 3, pp. 293-308, Apr. 24, 2000.

[28] K. D. Young, V. I. Utkin, and U. Ozguner, "A control engineer's guide to sliding mode control," IEEE Trans. Control Syst. Technol., vol. 7, no. 3, pp. 328-342, May 1999.

[29] B. Beltran, T. Ahmed-Ali, and M. El Hachemi Benbouzid, "Sliding mode power control of variable-speed wind energy conversion systems," IEEE Trans. Energy Convers., vol. 23, no. 2, pp. 551-558, Jun. 2008

[30] D. Xiang, R. Li, P. J. Tavner, and S. Yang, "Control of a doubly fed induction generator in a wind turbine during grid fault ride-through," IEEE Trans. Energy Convers., vol. 21, no. 3, pp. 652-662, Sep. 2006. 